Témoigner Témoigner. Entre histoire et mémoire

Getuigen Revue pluridisciplinaire de la Fondation Auschwitz

$123 \mid 2016$

Traduire le témoignage

\title{
Jasenovac: een litteken in de kroatische bodem
}

Jasenovac: une cicatrice sur le sol croate

\section{Frédéric Crahay}

Traducteur : Anneleen Spiessens

\section{(2) OpenEdition}

\section{Journals}

Édition électronique

URL : https://journals.openedition.org/temoigner/5480

DOI : $10.4000 /$ temoigner.5480

ISSN : 2506-6390

Éditeur :

Éditions du Centre d'études et de documentation Mémoire d'Auschwitz, Éditions Kimé

Édition imprimée

Date de publication : 1 octobre 2016

Pagination : 183-189

ISBN : 987 2-9600926-4-6

ISSN : 2031-4183

Référence électronique

Frédéric Crahay, «Jasenovac: een litteken in de kroatische bodem», Témoigner. Entre histoire et mémoire [Online], 123 | 2016, Online op 02 novembre 2021, geraadpleegd op 04 novembre 2021. URL: http:// journals.openedition.org/temoigner/5480 ; DOI: https://doi.org/10.4000/temoigner.5480

Tous droits réservés 


\section{Memorial site}

\section{JASENOVAC \\ EEN LITTEKEN IN DE KROATISCHE BODEM}

inds de oprichting van de onafhankelijke republiek in 1991 beantwoordt de site van Jasenovac niet meer aan het beeld dat de jonge Kroatische staat wil uitdragen in haar strijd om bevestiging en soms verdediging tegenover haar agressoren. Tussen 1945 en 1980, onder het bewind van maarschalk Josip Broz
Tito, bezocht elk lagereschoolkind in Joegoslavië de plek en bewandelden jaarlijks 300000 mensen de trieste vlakte waarop de site meteen na de oorlog werd ingericht. Sinds het overlijden van Tito in 1980 is Jasenovac geen verplichte bestemming meer voor schooluitstappen. De site moet het vandaag stellen met nog slechts •••
Jasenovac net na de bevrijding in 1945: de restanten van de oven van de voormalige steenbakkerij in Jasenovac III.

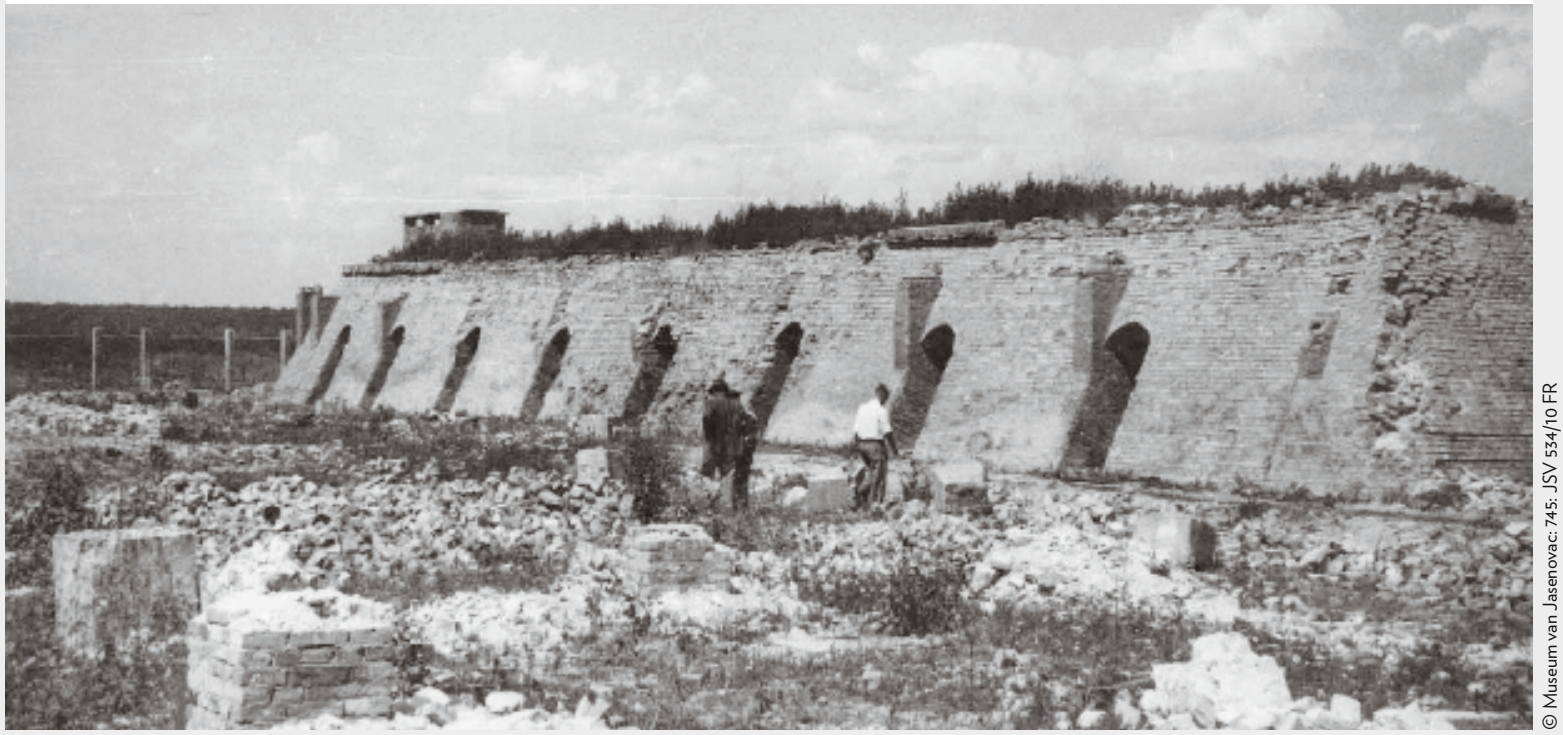


De tumuli op de vlakte van Jasenovac III symboliseren de gebouwen die
ooit stonden. $\cdots 11000$ bezoekers per jaar, grotendeels Serviërs, Bosniërs en vertegenwoordigers van de Joodse en Roma- en Sinti-gemeenschappen uit de landen van het det deze belangije herino kont

plek zo in verval is geraakt?

\section{JASENOVAC TIJDENS HET}

Het concentratiekamp van Jasenovac werd in augustus 1941 geopend doorde Kroatische fascistische Ustasubestond uit vijf deelkampen: Krapje
(Jasenovac I), Bročica (Jasenovac II) Ciglana (Jasenovac III, hier bevindt zich Ciglana (Jas Inovacill, hier bevindezich vandac IV) v). Het Sta Gradisha (Jasenowas geve thoof kanp, Jasenovac III, Werij bakkerifuit dejarentwing. In het dor zelf werd een ethische zulvering door zever werd een ethische zuivering doorentische

Tijdens de oorlogsjaren stond Jasenovac symbool voor de verschrikkingen kelijke Stast Kroatië (Nez de Onafhan-
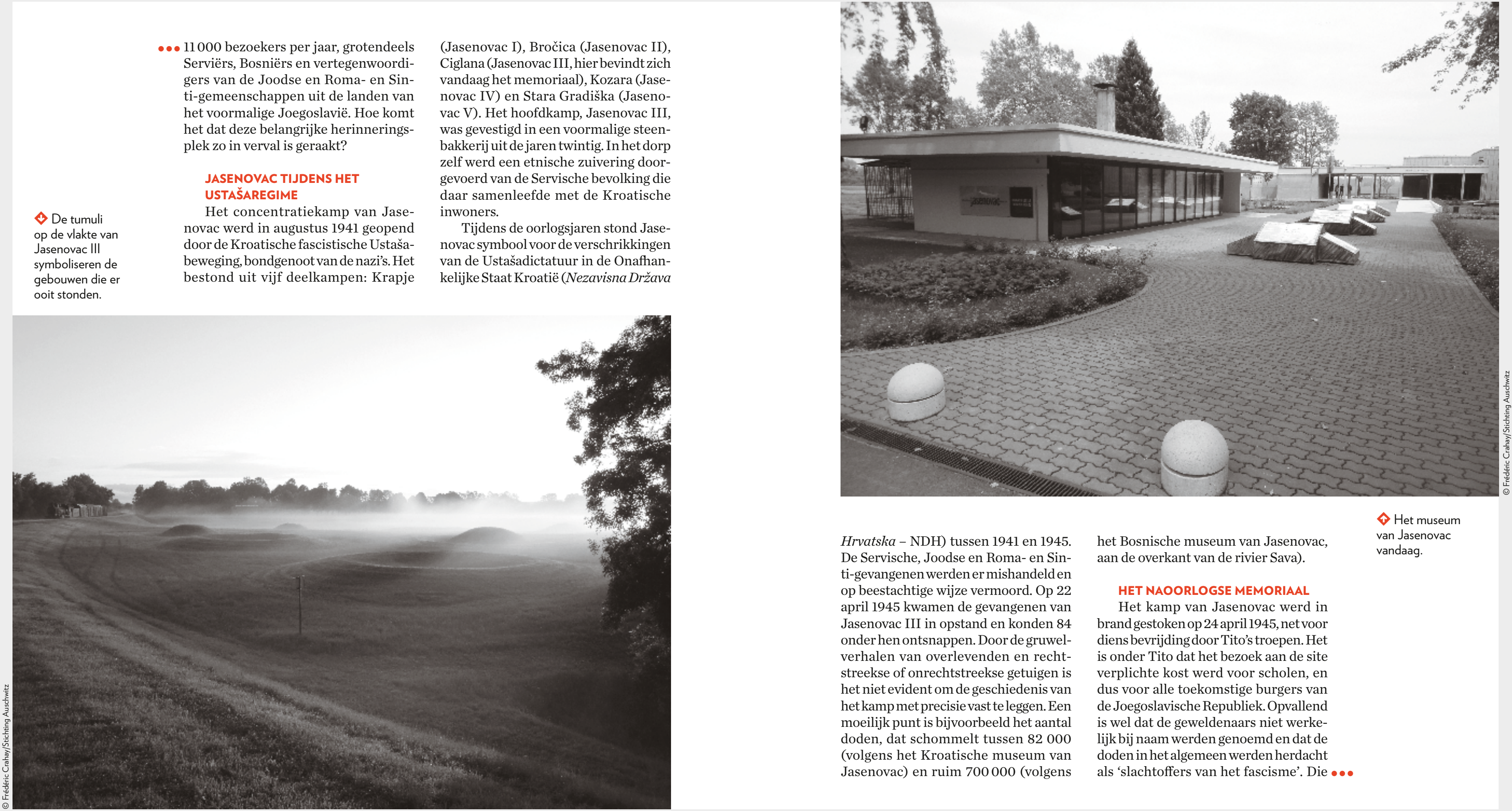

Hrvatska - NDH) tussen 1941 en 1945. De Servische, Joodse en Roma- en Sinti-gevangenerise op beestachtige wijze vermoord. Op 22 Jpril $1945 \mathrm{kwamen}$ de gevangenen van Jen onder r hals stris het niet videnton heeilik punt is bijvoorb tegen. Een dodilk punt is bijvoorbeld het aanta (volgens het Kroatis th museum van (volgens het Kroatische nuseum van

het Bosnische museum van Jasenovac, aan de overkant van de rivier Sava).

HET NAOORLOGSE MEMORIAL Het kamp van Jasenovac werd in brand gestoken op 24 april 1945, net voor bevrijding door Tito's troepen. Het s onder Tito dat het bezoek aan de site erplichte kost werd voor scholen, en dus voor alle toekomstige burgers van is wel desteriek. Opvallend lijk bij nat de geweldenaars niet werkedoden in warement dis 's hacto
४ Het museum van Jasenovac 


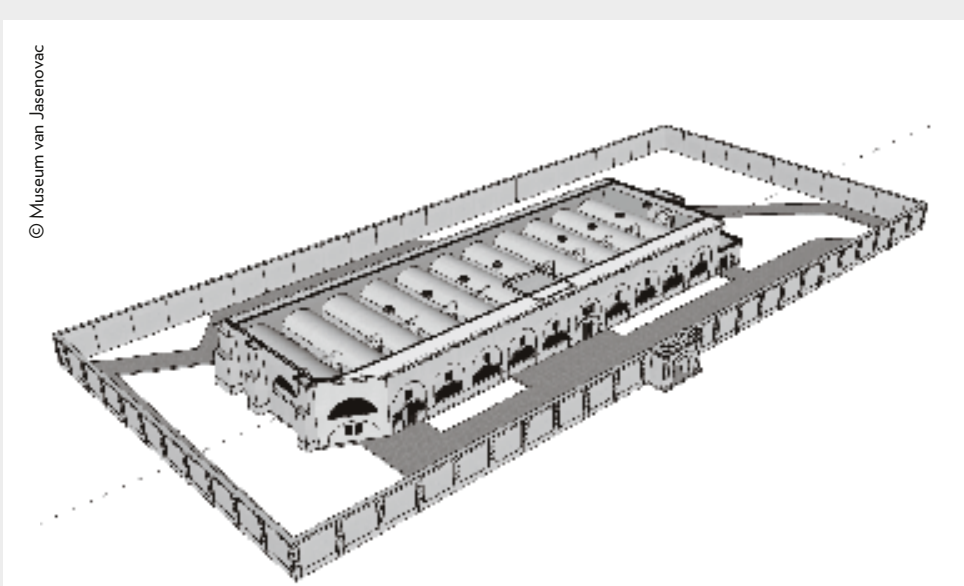

S) 3D-plan voor de renovatie van
het gevangenisgebouw van Stara Gradiška (Jaseno$\operatorname{vac} V)$.

.. keuze kaderde in de politiek van 'Broederschap en Eenheid' die het regime
oplegde om separatistische neigingen bij de verschillende Joegoslavische volkeren de kop in te drukken en wraakgevoelens te beteugelen. Pas twintig jaar na het einde van
var de Tweede Wereldoorlog, en door de niet-aflatende druk vanwege de families van de slachtoffers, werd in 1965 det betonnen monument is het werk Het betonnen monet werk van kunstenaar Bogdan Bogdanovic en stelt een bloem voor die volgens de

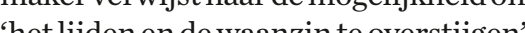
Enkele jaren later opende het bijbenoEnkele jaren later opende het bijbehorende museum de deuren.

De Kroatië en Servie in 1991 veranderde de zaak grondig. I debuurtvanhetdorp Jasenovacvonden gew hedenge op heden dragen de huizen er de spodet ve Servische troepen haalden het Duseun wan Jasenovac leeg. de docunracht nar de Bosin werden Baja La Na bitse Bosnische stad Banja Luka. Na bitse onderhandingen en de tussenkomst van het United on werden alle objecten herenigd. De Bosnische regering wilde zich ervan vergewissen dat de Kroaten van de gelegenheid geen gebruik maakten om compromitterende documenten over het over de Sava die de twee delen ve brug over de Sava, die de twee delen van het de oorlog niet. Sindsdien wordt het geschiedkundig onderzoek naar Jaseen Kroatië.

DE PLAATS VAN JASENOVAC IN HET KROATIË VAN VANDAAG De oorlog van 1991 - de Kroaten De oorlog van 1991 - de Kroaten prons landsoorlog en beschouwen die als een daad van agressie van een staat tegen en anningen averine stat - heef de spanning a angewakkerd die sinds par nieuwe won ook nieuwe wonden geslagen die nog steeds niet zijn geheeld. In Jasenovac komen die ongemakkelijke verhalen pijnlijk ve plek herinnert zo aan een

Jasenovac brengt het huidige Kroatië duidelijk in verlegenheid. De nieuwe staat zet dan ook voornamelijk in op , een site die verbindend werk (toch voor de Kroaten) in tegenstelling tot Jasenovac. Vukovar, aan de oevers van de Donau in oost-Kroatië, werd in Servische tenlang belegerd door de servische troepen en werd een martelaarsstad, een symbool van opoffering en helde in het Joegosla Tito weerd in het Joegoslavie van Koliner in het Kroatie van president doorVukovar door Vukovar. Het belangijhsteverschil tussen beide sites is dat Jasenovac het de oorlog neg Sind van de Kroatische bevolking tijdens de dat het moderne Kroatië niet te ster when slachtofer Ke boijgen ze een verplichte tweedarse krijgen ze een verplichte tweed agse

ie sinds 1952 een

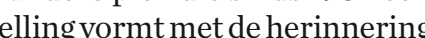

van Jasenovac is Bleiburg, waar aan het inde van de oorlog een massamoord plaatsvond. Talloze Kroatische vluchlelingen werden er gedood door Tito's Joegoslavische Volkleger. Het dorpje p de Oostenrijks-Sloveense grens was erst tegen wil en dank het toneel van een plechtigheid georganiseerd door Kroatische bannelingen. Die werd Tweede Wereldoorlog - een verleden

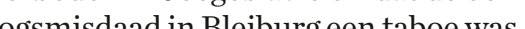

De ruïnes van de gevangenis van (Jasenovac V).

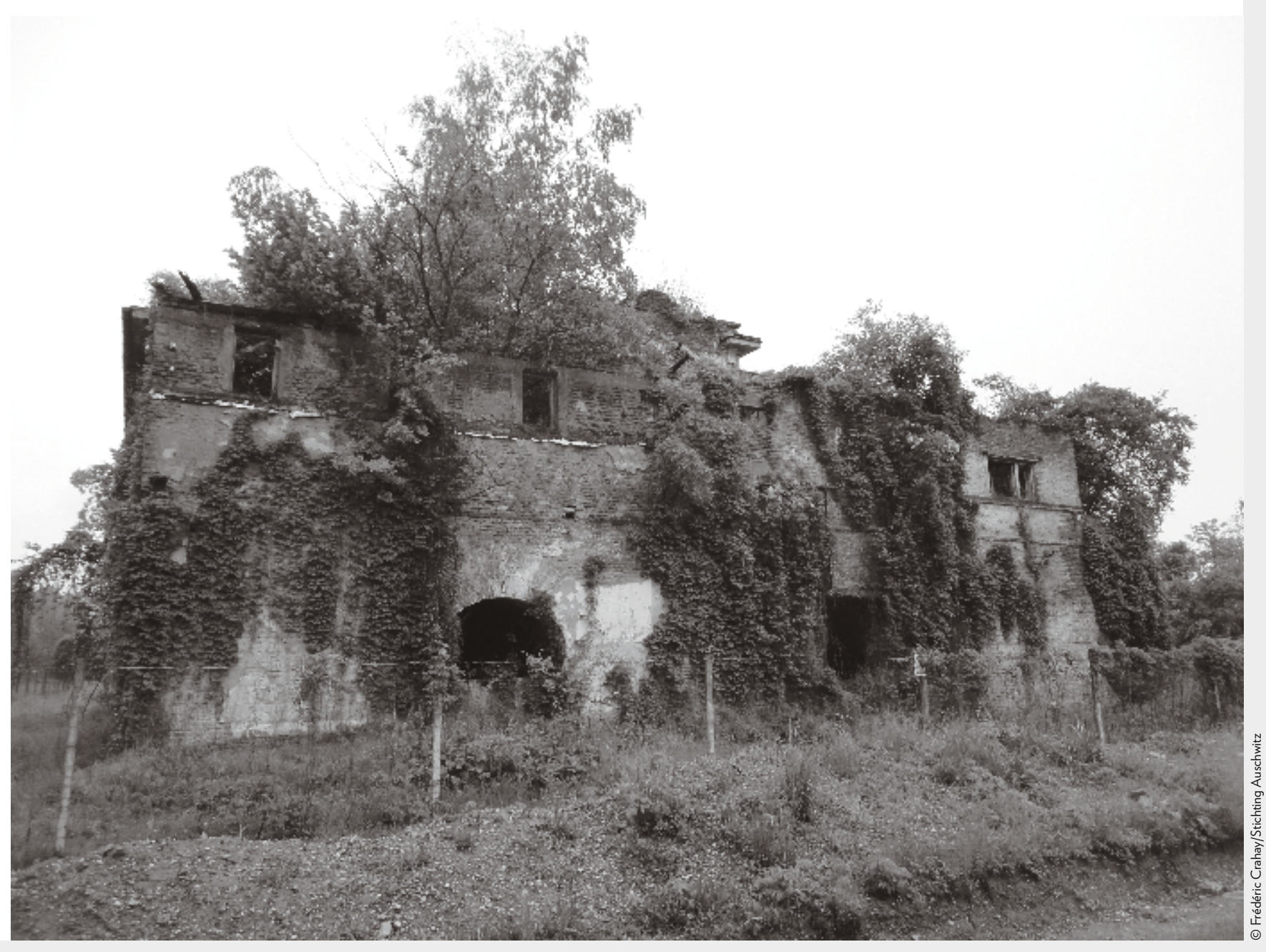


$\checkmark$ De bloem van Bogdan Bogdanovic op de voormalige appèlplaats van he concentratiekam
Jasenovac III.
-• maar na de onafhankelijkheid in 1991 kwam in de plats dat meer en meer politici it de Kroat mo uit de Kon vic, Oncr her Zlatko Hasanbegofic, een frumoln figu en ( do hij, dat Jasenovac in de Joegoslavische periode een monument werd voor de verwinning op het fascisme.

Het beleid van de huidige regering angevoerd door de nationalistische partij HDZ (Hrvatska Demokratska Zajednica - Kroatische Democratische Unie), en de Ustašasymbolen die weer opduiken in de straten van Kroatië, verntrusten verenigingen die begaan zijn van het fastischere de

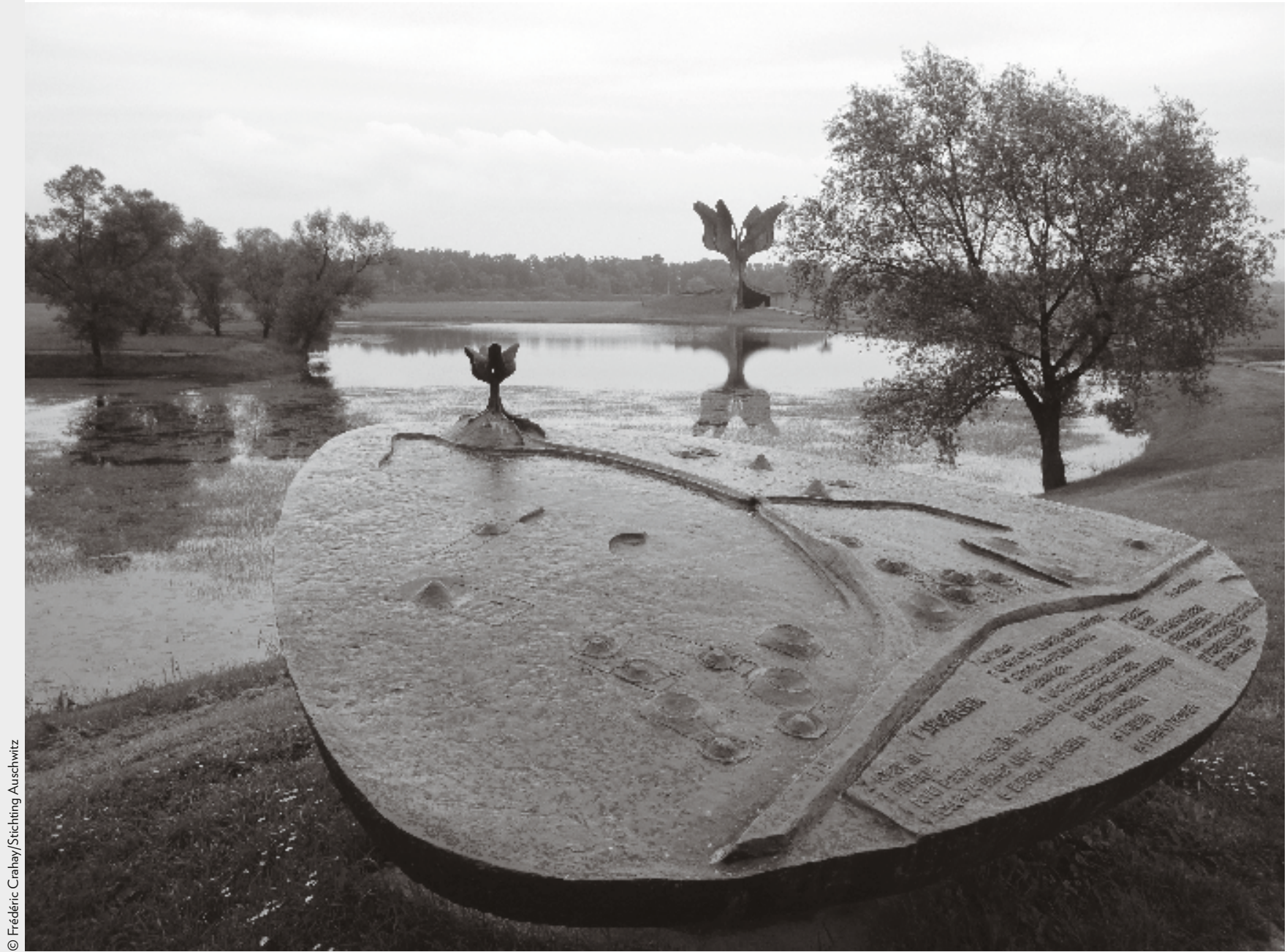

Tweede Wereldoorlog. De officiële herdenking van Jasenovac op 22 april, de dag van de opstand in het kamp, verlie niet helemaal volgens plan in 2016. Als protest tegen het beleid van de Kroatische regering hebben Servische, Joods en Roma- en Sinti-organisaties hun eigen plechtigheid gehouden.

Voor het museum van Jasenovac hebben de dalende bezoekersaantallen waardor het op dit moment moeilijk wordt om he site te mone moelijk Wordt on de site te onderhouden. Zo is Stara Gradiska (Jasenovac $V$ ) dingend toe aan renovate. Het kamp ligt op 45 tijdens de oorlogvouwen en kinden tijcens de oonlog vouw en kinderen van Servische, Joodse, Roma- en Sindie dant wit de Oostenrijks die dateert uit de Oostenrijks-Hongaare III, Wet hoofdgewouw sta recht, mar bevindt recht, Mar belijke stat Eriser dagen in budget directien een het gebouw stila in verval genten

BESLUIT

Het memoriaal van Jasenovac bevindt zich op een keerpunt in haa bestaan. Het wetenschappelijk onderzoek rond de geschiedenis ervan ontwikkelt zich verder, maar ook in Kroatie is dat vaak financieel afhankelijk van het politieke veld. De oorlog in ex-Joerovië in de jaren negentig heft de goslave in de jaren zaken nog complexergemaakt en liet de ter. Het huidige Kroatië moet de strijd ter. Het his dige Kroatie not de strijd aanbinden methaar eigen demonen en betekenisvolle sites als Jasenovac de plek geven die ze verdienen in het col- bonden aan de Tweede Wereldoorlog en de Holocaust hebben echter tot zoveel verdeeldheid geleid bij onderzoekers. Verdeeldheid die eerst op het politieke niveau moet worden opgelost alvorens ente is voor een sereen debat onder historici.

Frédéric Crahay Stichting Auschwitz Vertaling: Anneleen Spiessens 